Derleme Makalesi - Review Article

\title{
Yüksek Basınç Uygulamasının Et ve Et Ürünlerinin Güvenliği ve Raf Ömrü Açısından Rolü
}

\author{
Cemalettin Sarıçoban ${ }^{1 *}$, Mahmood Shakir Mahmood ${ }^{2}$, Rand Kadhim Bahr Al-Murjan ${ }^{3}$ \\ Geliş / Received: 22/04/2020 \\ Revize / Revised: 12/09/2020 \\ Kabul / Accepted: 14/09/2020 \\ ÖZ
}

Yüksek basınç (YB) ilk olarak 19. yüzyılın sonunda malzeme kimyası alanında tanıtılmıştır. Gıda endüstrisinde ilk yüksek basınç uygulaması ise Hite tarafından 1899 'da süt ve meyve ürünlerini pastörize etmek için uygulanmıştır. Tüketicilerin, tükettikleri gıdaların besin değerinde kayıplar olmayacak şekilde işlenmiş gıdalara olan ilgisine paralel olarak gıda işleme ve muhafaza açısından yeni teknolojiler geliştirilmektedir. Bunlardan biri de yüksek basıncın gıdalara uygulanmasıdır. Yüksek basınçlı işleme, gıdaları birkaç dakika belirli bir sıcaklıkta 100 ila $600 \mathrm{MPa}$ arasında yüksek bir basınç seviyesine maruz bırakmayı amaçlayan bir tekniktir. Yüksek Basınç (YB) uygulamaları, özellikle mikrobiyolojik inaktivasyon sağlamanın yanında gıdaların vitamin, mineral, tat, renk ve görünüşünde önemli bir değişikliğe neden olmamaktadır. Bu nedenle, 1sıl işlem uygulamaları için önemli bir alternatif oluşturmaktadır. YB uygulamaları sıvı gıdalara başarıyla uygulanabildiği gibi et ve et ürünleri gibi gıdalara da uygulanabilmektedir. Yüksek basınç, raf ömrünün büyük ölçüde, özellikle dilimleme ve paketleme işlemleri sırasında iyi hijyen/üretim uygulamalarına bağlı olduğu hazır yemeklerde mikroorganizmaları etkisiz hale getirmenin uygun bir yoludur. Bu derlemede, et ve et ürünlerinin güvenliğini arttırmada ve raf ömrünü uzatmada yüksek basıncın rolüne değinilmiştir.

\footnotetext{
1*Sorumlu yazar iletişim: cscoban@selcuk.edu.tr (https://orcid.org/0000-0001-9898-0884)

Gıda Mühendisliği Bölümü, Selçuk Üniversitesi, 42075 Konya

2İletişim: mahmoudshakir@yahoo.com (https://orcid.org/0000-0003-2204-2490)

Gıda Mühendisliği Bölümü, Selçuk Üniversitesi, 42075 Konya

3̇letişim: ranoosh kb@yahoo.com (https://orcid.org/0000-0001-9804-6768)

Gıda Mühendisliği Bölümü, Selçuk Üniversitesi, 42075 Konya
} 


\title{
The Role of High-Pressure Application for the Safety and Shelf Life of Meat and Meat Products
}

\begin{abstract}
High pressure (HP) was first introduced into the field of material chemistry at the end of the $19^{\text {th }}$ century. The first high pressure application in the food industry was applied by Hite in 1899 to pasteurize milk and fruit products. New technologies are being developed in terms of food processing and preservation in line with the interest of consumers in processed foods in such a way that there is no loss in nutritional value of the food they consume. One of these is the application of high pressure to foods. High pressure processing is a technique aimed at exposing food to a high-pressure level between 100 and $600 \mathrm{MPa}$ at a given temperature for a few minutes. In addition to providing microbiological inactivation, High Pressure (HP) applications do not cause a significant change in the vitamin, mineral, taste, colour, and appearance of foods. Therefore, it constitutes an important alternative for heat treatment applications. HP applications can be successfully applied to liquid foods as well as foods, such as meat and meat products. High pressure is a convenient way of neutralizing microorganisms in ready meals, where its shelf life is largely dependent on good hygiene / production practices, especially during slicing and packaging processes. In this review, the role of high pressure in increasing the safety and extending shelf life of meat and meat products is discussed.
\end{abstract}




\section{Gİiș}

Yüksek basınç (YB) ilk olarak 19. yüzyılın sonunda malzeme kimyası alanında tanıtıldı. Gıda endüstrisinde ilk yüksek basınç uygulaması, Hite tarafından 1899'da süt ve meyve ürünlerini pastörize etmek için uygulandı [1]. Daha sonra bakteri sporlarının yüksek basınca dayanıklılığı konusunda araştırmalar yapıldı [2] ve 1946'da Amerikan fizikçi P.W.'ye özellikle yüksek basınçlı işlemlerin yürütülmesi için tasarlanmış hermetik bir gemi icat ettiği için Nobel Fizik Ödülü verildi [3]. Bu teknik ilk olarak 1980'lerin sonunda Japonya'da gıda endüstrisinde uygulandı. Paskalizasyon olarak da adlandırılan işlem; ürünün belirli bir süre ve sıcaklık için çok yüksek hidrostatik basınçta (YHB, 100-1000 MPa) tutulmasından oluşur. YHB işlemi, gıdalardaki patojenik ve bozulmaya neden olan mikroorganizmaların inaktivasyonunu sağladığı için, 1sıl işlemlere alternatif, 1sıl olmayan bir işlem olarak kabul edilir. Japonya'daki ilk uygulamasından bu yana, bu yeni teknoloji, teknolojik ve ticari yönden önemli bir gelişme kaydetmiştir. Günümüzde dünya genelinde 160'dan fazla endüstriyel gemi kullanılmaktadır. Ayrıca, et ürünlerinin yüksek basınçla işlenmesi, son yıllarda alınan çok sayıda patentin kanıtladığı gibi hızlı büyüyen bir sektördür. ele alınmıştır.

Bu derlemede, et ve et ürünlerinin güvenliğini arttırmada ve raf ömrünü uzatmada yüksek basıncın rolü

\section{YÜKSEK BASINÇLI KORUMA TEORİSI VE GIDALARIN DEKONTAMINASYONUNDA ETKİ ŞEKLİ}

Yüksek basınçlı işleme, gıdaları birkaç dakika belirli bir sıcaklıkta 100 ila $600 \mathrm{MPa}$ arasında yüksek bir basınç seviyesine maruz bırakmayı amaçlayan bir tekniktir [4]. Bu teknoloji, basınç altındaki gıdaların davranışını belirleyen iki prensibe dayanmaktadır [5]. İlk olarak, reaksiyon dengesi üzerindeki etkilerin altında yatan önemli bir ilke, Le Chatelier'in prensibi olarak bilinir; buna göre, hacimdeki bir düşüşün neden olduğu etki, basınçla veya bunun tersi yönde bir artışla arttırılabilir [6]. Bu nedenle, basıncın uygulanması fiziksel ve kimyasal değişikliklere (kimyasal reaktivite ve reaksiyon, moleküler konfigürasyonda değişiklik, faz geçişi) neden olur. Fiziksel olarak basınçtaki bir artış, moleküller arasındaki mesafenin azalmasına neden olur [7]. Yüksek basınçlı muamele sırasındaki fiziksel sıkıştırma, gıda kompozisyonuna bağlı olarak adyabatik ısıtma yoluyla, sıcaklıkta $100 \mathrm{MPa}$ başına yaklaşık $3{ }^{\circ} \mathrm{C}^{\prime}$ lik bir artışa neden olur [8]. Kimyasal değişimler minimumdur. Sadece hidrojen bağları, iyonik bağlar ve kovalent olmayan bağlar basınçla bozulur [9]. Basınç, mikrobiyal gelişmeyi önemli ölçüde etkiler. Gıdanın korunmasına katkıda bulunan mikrobiyal inaktivasyon aslında, hücre zarlarında basınca bağlı hasar, protein denatürasyonu, enzim aktivitesindeki değişiklikler ve ribozomun konformasyonu sonucu meydana gelir [10]. Ancak, basıncın gıda bileşenleri üzerinde de etkileri vardır. Dolayısıyla, protein denatürasyonu tekstürü, gıda kalitesi üzerinde olumlu veya olumsuz etkiler ile değiştirebilir. Kovalent bağlar basınçtan etkilenmediğinden, vitaminler ve lezzet verici bileşikler değişikliğe uğramaz [9]. Sonuç olarak, mikroorganizmalar yüksek basınçlı işlemlerle hedeflenirken, gıdaların besleyici ve duyusal özellikleri geleneksel bir ısıl işleme kıyasla korunmaktadır.

Yüksek basınç etkisiyle ilişkili ikinci prensip, basıncın tüm ürün boyunca basınç gradyanı olmadan anında ve düzgün bir şekilde iletildiğini belirten izostatik prensiptir [10]. Böylece basınç, izostatik basınç olarak tanımlanır. Basınç, gıdanın boyutundan ve geometrisinden bağımsız olarak uygulanır, çünkü çekirdeğe basıncın aktarılması kütle veya zamana bağlı değildir [4]. Sonrasında, basınç uzaklaştırıldığında gıda orijinal haline döner.

Yüksek basınçlı cihaz; basınçlı bir akışkan, genellikle su, basınç üretim sistemi, malzeme taşıma sistemi ve sıcaklık kontrol cihazı kullanılarak ürüne basıncın iletildiği bir kaptan oluşur (Şekil 1) [11].

Ürün ambalajı, basınca ve su direncine dayanacak şekilde esnek olmalıdır. Paketlenmiş gıdalar basınçlı kabın içerisine konulur. Hazne kapatılır ve hacim düşürülerek (doğrudan sıkıştırma) veya basınç ileten sıvıyı bir yüksek basınçlı pompa (dolaylı sıkıştırma) vasıtasıyla hazneye enjekte ederek basınç arttırılır. Sıvı, istenen basınca ulaşılıncaya kadar gıda etrafındaki havanın yerini değiştirir. Ardından, pompa durdurulur ve istenen basınç verilen süre boyunca korunur. İşlem tamamlandığında, atmosfer basıncına geri dönen, basınç ileten sıvının serbest bırakılmasıyla ambalaj sıkıştırılır. Basınçlı kap açılır ve paketlenmiş gıda çıkarılır [12]. 


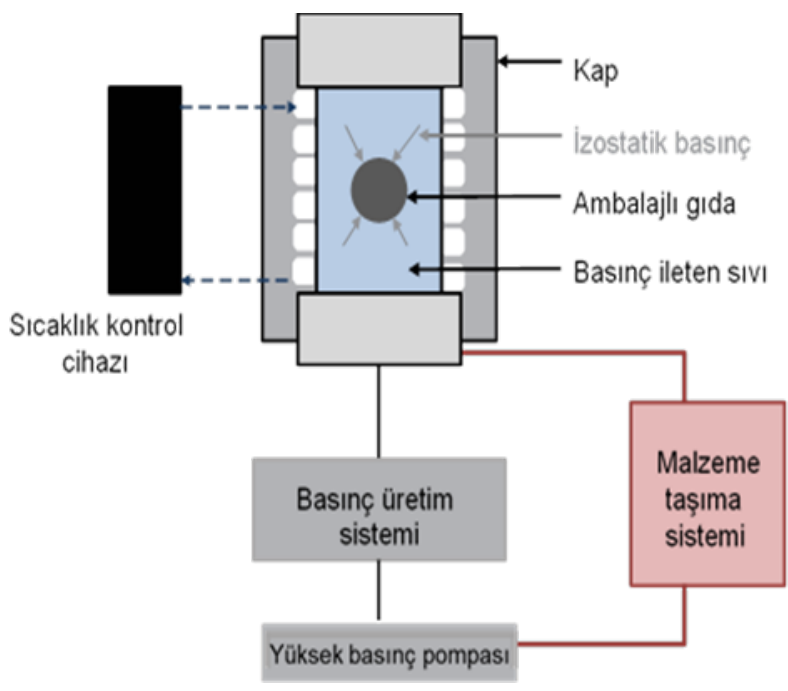

Şekil 1. Yüksek basınçlı ekipman ilkesinin şeması [11].

Yüksek basınç verimini etkileyen çeşitli faktörler vardır. Bunlar; mikroorganizma türü, basınç kinetiği, sıcaklığın etkisi, ortamın kompozisyonu, $\mathrm{pH}$ ve su aktivitesidir [13].

\section{ET ÜRÜNLERININ GÜVENLIGĞINI ARTIRMAK IÇi̇N YÜKSEK BASINÇ UYGULAMASI}

Et ve et ürünleri Salmonella spp., Campylobacter jejuni/coli, Yersinia enterocolitica, Verotoxigenic Escherichia coli (VTEC) ve belli bir yere kadar L. monocytogenes ile insan enfeksiyonlarının çoğunu barındırır. Sağlıklı hayvanların gastrointestinal kanalının bulunduğu bölgelerde, transformasyon, taşıma ve çapraz kontaminasyon yoluyla gıdalara aktarılır. Taze kırmızı ette Salmonella spp., C. jejuni/coli, Y. enterocolitica ve VTEC oluşumları; organizma, coğrafi faktörler, çiftçilik ve/veya et üretim uygulamaları gibi bir dizi faktöre bağlı olarak değişebilir [14]. Çoğu durumda hijyen göstergesi olarak kabul edilen E. coli, bazı çok patojenik serotipleri içerir. VTEC arasından E. coli O157:H7 böbrek yetmezliği gibi ciddi komplikasyonlara neden olabileceği için ciddi bir halk sağlığı riski oluşturabilir. Çalışmaların çoğu, E. coli, $16^{\circ} \mathrm{C}^{\prime}$ de marine edilmiş dana bonfile içinde 6 dakika boyunca $600 \mathrm{MPa}$ tarafından ve $6{ }^{\circ} \mathrm{C}$ 'de pişirilmiş ve 1 șll işlemden geçirilmiş jambondan tamamen etkisiz hale getirilebildiğinden yüksek basınca duyarlı olduğunu göstermiştir $[15,16]$. E. coli O157:H7 ayrıca 5 dakika boyunca $20^{\circ} \mathrm{C}^{\prime}$ de $700 \mathrm{MPa}$ ve 5 dakika boyunca $19{ }^{\circ} \mathrm{C}$ de $483 \mathrm{MPa}$ da, kuru fermente salamlarda ve çiğ kıyma etinde uygulanan işlemlerden sonra tamamen etkisiz hale getirildi $[17,18] .500 \mathrm{MPa}$ 'ın altındaki yüksek basınç işlemlerinin $E$. coli ve $E$. coli O157:H7'nin inaktive edilmesinde etkisiz olduğu belirlenmiştir. Model et sistemi [19] ve sığır köftesi [20] üzerinde $400 \mathrm{MPa}$ 'da gerçekleştirilen muameleler, sırasıyla 4.5 (8 aşılanmış) ve 2.45 $\log 10$ (7 aşılanmış) inaktivasyonuna yol açmıştır.

L. monocytogenes önemli bir halk sağlı̆̆ı sorununu teşkil eder. Bu nedenle birçok çalışma, yüksek basıncın et ürünlerinde L. monocytogenes'in inaktive edilmesi üzerindeki etkisini ele almıştır [21-25]. L. monocytogenes'in buzdolabında gelişebilme özelliğinden dolayı YHB işlemlerinin, hayatta kalan hücrelerin soğutulmuş depolama sırasında tekrar gelişmesine izin vermeyecek kadar etkili olması gerektiği bilinmelidir. Gram-negatif bir bakteri olan Salmonella; kıyılmış tavukta, et örneğinde [26], fermente edilmiş [27] ve kanatlı sosislerinde [28] $400 \mathrm{MPa}$ 'dan itibaren yapılan YHB işlemleri [29] ile genellikle önemli ölçüde inaktive edildi.

Jofré ve ark. [24], gida kaynaklı patojenlerden L. monocytogenes, Salmonella enterica, S. aureus, Y. enterocolitica ve Campylobacter jejuni ile hijyen göstergesi olan $E$. coli ve bozulmaya neden olan mikroorganizmalar (Debaryomyces hansenii ve LAB) ile yapılan testlerle, pişmiş ve isıl işlem uygulanmadan kurutulmuş jambon ve marine edilmiş dana etinin güvenliğini arttırmak için yüksek basıncın kullanıldığını gözlemlemişlerdir [16]. $600 \mathrm{MPa}$ da uygulanan işlem; E. coli, mayalar ve gida kaynaklı patojenlerden $L$. monocytogenes, Salmonella, $Y$. enterocolitica ve $3.5 \mathrm{log} \mathrm{cfu} / \mathrm{g}$ 'da aş1lanan $C$. jejuni'nin etkin şekilde inaktivasyonunu sağlamıştır ve $Y$. enterocolitica'nın en az aktif olan ve $10 \mathrm{~g}$ üründe saptanmadığı bildirilmiştir. 
Tamamen inaktivasyonun sağlandığı marine edilmiş dana eti hariç tüm ürünler için $10 \mathrm{cfu} / \mathrm{g}^{\prime} ı$ altındaki $L$. monocytogenes ve Salmonella spp. konsantrasyonları bulunabilir. Bununla birlikte, S. aureus, diğer patojenik aşılanmış türler arasında YHB işlemine en dirençli mikroorganizmadır. Marine edilmiş sığır etinde en yükssek inaktivasyon $\left(2.7 \log _{10} \mathrm{cfu} / \mathrm{g}\right)$ elde edilmiştir [16]. S. aureus'un yüksek basınca karşı direnci diğer araştırmacılar tarafindan da gözlemlenmiştir.

\section{ET ÜRÜNLERININ RAF ÖMRÜNÜ UZATMAK İÇİN YÜKSEK BASINÇ UYGULAMASI}

Yüksek basınç, raf ömrünün büyük ölçüde, özellikle dilimleme ve paketleme işlemleri sırasında iyi hijyen/üretim uygulamalarına bağlı olduğu, hazır yemeklerde mikroorganizmaları etkisiz hale getirmenin uygun bir yoludur. Bu nedenle, birçok çalışma, özel sosislerin raf ömrünü uzatmak için YHB uygulamasının kullanımı ile ilgilidir [28, 30]. Simonin ve ark. [13], YHB işlemleri kullanarak kuru-kürlenmiş jambon [15, 16] ve sosisler [31], pişmiş jambon $[15,25]$ ve pişmiş sosisler vb. [32, 33] et ürünlerinin raf ömrünü uzatmayı amaçlayan çalışmalar yapmıştır.

Ette bozulmaya neden olan mikroorganizmalar esas olarak enterobakterler ve laktik asit bakterileri (LAB)'nden oluşurken, düşük sıcaklıktaki değişimler temelde psikrotroflara bağlıdır. Ette Pseudomonas türlerinin baskın olduğu psikrotrofların, yüksek basınçlara karşı mezofillerden daha duyarlı oldukları düşünülmektedir [13]. Bu nedenle, 300 ve $450 \mathrm{MPa}$ 'da yapılan çalışmaların, Pseudomonas'1 [34, 35] tamamen etkisiz hale getirdiği gösterilmiştir $[35,36] .31{ }^{\circ} \mathrm{C}^{\prime}$ de 6 dakika boyunca $600 \mathrm{MPa}$ da uygulanan yüksek basıncın, $4{ }^{\circ} \mathrm{C}^{\prime}$ de 120 günlük depolama süresi boyunca kuru-kürlenmiş ve pişmiş jambonda mayaları ve enterobakterleri tamamen etkisiz hale getirdiği görülmüştür $[15,26]$. Dolayısıyla, YHB işlemi bu iki floranın üreme ve gaz üretme potansiyelini azaltmada etkili olmuştur. Bununla birlikte, YHB işleminin LAB'yi inaktive etmesinin, et ürünlerinin doğal yapısına bağlı olduğu gösterilmiştir. Her ne kadar $7{ }^{\circ} \mathrm{C}^{\prime} \mathrm{de} 20$ dakika boyunca uygulanan $400 \mathrm{MPa}$ 'lı işlem dilimlenmiş-pişmiş jambonda LAB popülasyonunda önemli bir azalma sağlamış olsa da [37], sosis üzerinde yapılan $15^{\circ} \mathrm{C}^{\prime} \mathrm{de} 10$ dakika boyunca $600 \mathrm{MPa}$ 'lık daha yüksek bir basınç işlemi, LAB sayısı üzerinde neredeyse hiçbir etki yapmamıştır [38]. Aslında, kuru-kürlenmiş ve marine edilmiş gıda ürünlerinde LAB'nin tamamen inaktive edilmesine olanak sağlamıştır, ancak 60 günlük depolamada pişmiş et ürünlerinde yeniden gelişme gözlenmiştir, bu da işlem görmemiş ve basınç uygulanan pişmiş et ürünlerine benzer bir son mikrobiyal yüke yol açmıştır [15]. Jofré ve ark. [16], YHB işlemi, pişmiş jambonda LAB'nin kuru-kürlenmiş jambondan daha fazla inaktive (4.6 ve $1.6 \log _{10}$ ) edilmesine olanak sağlamıştır. Bununla birlikte, muhtemelen bu ürünlerdeki düşük miktar nedeniyle, kuru-kürlenmiş ürünlerde soğukta depolama boyunca LAB yeniden ortaya çıkmamıştır, oysa $4{ }^{\circ} \mathrm{C}$ 'deki 120 günlük depolamanın sonunda basınçlı ve işlem görmemiş pişmiş ürünlerde LAB popülasyonu aynı seviyeye ulaşmıştır [16].

İlginç bir şekilde, yüksek basınç uygulaması her zaman hızlı mikrobiyal inaktivasyona yol açmaz, fakat popülasyonun azalmasını geciktirir. Bu, sosislerin Pseudomonas ve Enterobacteria için $15{ }^{\circ} \mathrm{C}$ 'de 10 dakika boyunca 300-600 MPa ile muamelesinden sonra gözlenmiştir, bu da YHB'den hemen sonra belirgin bir mikrobiyal azalmaya yol açmazken, bakteriler ertesi gün saptanamaz hale gelmiştir [38]. Öte yandan, $400 \mathrm{MPa}$ üzerindeki yüksek basıncın bakteri geri kazanımını etkilediği ve bakteri üremesinin gecikmesine neden olduğu gösterilmiştir $[15,16,28]$. Bununla birlikte, bazı durumlarda, YHB'den sonra bakteri çoğalması, yüksek basınçtan sonra elde edilen hızlı mikrobiyal azalmanın yararlarını göz ardı etmektedir. Garriga ve ark. [26] tarafından, suyla homojenize edilmiş-pişmiş-işlenmemiş 20 günden daha kısa bir süre sonra basınç uygulanmış olan jambonun (10 dakika boyunca $17^{\circ} \mathrm{C}$ 'de $\left.400 \mathrm{MPa}\right) \mathrm{LAB}$ ve E. coli popülasyonu gözlemlenmiştir. Geri kazanımın, gıda bileşenine ve özellikle de atıkların [39] ya da yağın [31] varlığına, ürün hacmine [16] bağlı olduğu ve YHB işleminden önce bir pişirme aşamasının olması $[15,26]$, YHB işlemlerinin ardından mikrobiyal büyümeyi kontrol etmeyi dikkate almak önemli özelliklerdir.

\section{YÜKSEK BASINÇLA UYARILAN ETIN MODIFIKASYONU}

\section{A. Yüksek Basincin Et Tekstürü Üzerine Etkisi}

İşleme koşullarına, et bileşimine ve hazırlanmasına (çĭğ, pişmiş, kuru vb) bağlı olarak yüksek basınçtan sonra çok çeşitli dokusal değişiklikler gözlenmiştir [40]. Düşük sıcaklıktaki yüksek basıncın, ölümden birkaç saat sonra uygulandığında eti yumuşatabileceği kabul edilmiştir [40, 41]. Bununla birlikte, rigor mortis sonrası 
uygulandığında, yüksek basıncın yumuşatma üzerindeki ters etkisi sıklıkla rapor edilmiştir [42]. Sonuç olarak, Sun ve Holley [42], yüksek basıncın iki temel etkisini, kas olgunlaşması, yani rigor mortis ve sıcaklık ile ilgili olarak, uygulama zamanının bir fonksiyonu olarak özetlemişlerdir. Basınç, rigor mortis öncesi et üzerine uygulandığında ette düşük basınçlı $(<200 \mathrm{MPa})$ işlemenin yumuşatma etkisi gözlenirken, rigor mortis sonrası etin yumuşamasını sağlamak için daha yüksek sıcaklığın, yüksek basınçlı işlem ile birleştirilmesi gerekir. Rigor mortis sonrası sığır kasının [43] ve 400 MPa'da işlem gören tavuk kasının sertliğinde, yüksek basınçtan kaynaklanan bir artış gözlenmiştir [44, 45]. Benzer şekilde, $520 \mathrm{MPa}$ 'da uygulanan işlem, sığır kasının sertliğinin artmasına neden olmuştur [46]. Aksine, $8{ }^{\circ} \mathrm{C}$ 'de $500 \mathrm{MPa}$ 'da yüksek basınçlı muameleden sonra sığır eti yumuşaklığında bir artış gözlenmiştir [47]. Bitkisel orijinli enzimler, etlerin çözünebilir proteinini kolayca hidrolize edebilir. Enzimatik katkılarla gevrekleştirme amacı enzimin bağ doku (kollagen ve elastin) üzerine etkisi ile gerçekleşmektedir [48]. Elastin üzerine etkili olan papain'in, sığır kasında 100 ila 300 MPa'a kadar yüksek basınçlı işlemden önce enjeksiyonunun, et sertliğinin artmasını önlediği bulunmuştur [49].

Jambon gibi işlenmiş et ürünlerinde de yüksek basınca bağlı sertlik gözlenmiştir. 6 dakika boyunca $15{ }^{\circ} \mathrm{C}$ 'de 500 MPa'lık bir YHB muamelesi, 50 günlük depolama süresi boyunca yumuşamada bir azalmaya neden olmuştur [50]. $500 \mathrm{MPa}$ ve $65^{\circ} \mathrm{C}$ 'de yüksek basınçla işlenmiş pişmiş sosisler, sertliğini kaybetmiş ve 40 dakika boyunca $80-85^{\circ} \mathrm{C}^{\prime}$ de 1 siyla pişirilen pastörize edilmiş sosislere kıyasla daha düşük ağıllık kaybıyla birlikte yapışkanlık kazanmıştır [51]. Çiğ et üzerinde yapılan çalışmalar, pişirmeden önce yapıldı̆̆ında yüksek basıncın, yalnızca pişmiş etlere kıyasla jel esnekliğini arttırma eğiliminde olduğunu göstermiştir [52] ve pişirme kayıplarını azaltmışıtır [53]. Yüksek basınç ve ısıl işlemlerin birleştirilmesi, ısı kaynaklı protein denatürasyonu olarak et dokusunun değişken bir modifikasyonuyla sonuçlanmıştır. Genel olarak, yüksek basınçlı muamele sırasında sıcaklığın $70{ }^{\circ} \mathrm{C}$ 'nin üzerine çıkarılması, daha düşük sertlik ve görünür elastikiyet [54] fakat daha yüksek yapışkanlık ile sonuçlanmıştır [55]. Çiğ devekuşu sosislerinin jeli, sıcaklık $40{ }^{\circ} \mathrm{C}^{\prime} \mathrm{den} 60^{\circ} \mathrm{C}$ 'ye yükseldiğinde kuvvetlenmiş ve serbest su miktarı, ısıl işlem arttıkça azalmışıır [56, 57]. Et hamurların 200 veya $400 \mathrm{MPa}$ 'da ve $70-80{ }^{\circ} \mathrm{C}^{\prime} \mathrm{de}$ işlemek, yalnızca pişmiş örneklerde bulunanlardan daha iyi yağ ve su tutulmasını sağlamıştır [58]. Ürün formülasyonunun ve örneğin tuz içeriğinin, et hamurlarında doku ve suyun tutulmasını etkilediği gösterilmiştir [52, 58]. Et dokusunun yüksek basınç uygulaması ile değiştirilmesinin altında yatan mekanizmalar, miyofibriller proteinlerinde depolimerizasyon, çözünme, denatürasyon ve agregasyondur [59, 60].

\section{B. Yüksek Basıncın Etin Oksidasyonu Üzerine Etkisi}

Birçok çalışma, kanatlı eti ve et ürünlerinde soğutarak depolama sırasında hemen [61] veya sonra uygulanan yüksek basınçlı işlemlerin ardından lipit oksidasyonunun gözlenebileceğini göstermiştir [62]. Lipit oksidasyonu, genellikle istenmeyen bir ransidite ve kötü lezzet oluşturması ile ilişkilidir. Bu nedenle, yüksek basınçlı işlemenin potansiyel olarak bu zararlı özelliğine çok dikkat edilmiştir. Genel olarak, $300 \mathrm{MPa}$ 'ın altındaki yüksek basınç, lipit oksidasyonu üzerinde çok az etkiye sahiptir [13]. Bununla birlikte, ikincil oksidasyon ürünlerinin üretimi ile birlikte basınç seviyesiyle lipit oksidasyonunun arttığı gösterilmiştir. $600 \mathrm{MPa}$ 'n üzerindeki basıncın, vakumla paketlenmiş tavuk göğüs kasında 10 günlük soğutulmuş depolamadan sonra lipit oksidasyonunu arttırdığı gösterilmiştir [63]. Beltran ve ark. [62] $500 \mathrm{MPa}$ 'da ve $50{ }^{\circ} \mathrm{C}^{\prime}$ de 30 veya 60 dakika boyunca işlenen çiğ kıyılmış tavuk etlerinde lipit oksidasyonunun geciktirilmesine yardımcı olması için vakumlu ambalajın kullanılması gerektiğini ifade etmişlerdir. Nitekim, yüksek basınçlı işlem görmüş ürünlerdeki ransiditeyi en aza indirgemek için önerilen bir strateji, $\mathrm{N}_{2}$ ve $\mathrm{CO}_{2}$ [64] veya vakumlu paketleme [65] ile modifiye atmosfer altında ambalaj kullanılmasıydı. Paket içerisindeki oksijen konsantrasyonu, soğutmalı depolama sırasında düşürüldüğünde lipit oksidasyonunu etkilemiştir, oysa yüksek basınçlı işlemin kendisinde herhangi bir etkisi olmadığı görülmüştür [66].

Yüksek basınçlı işlemden sonra et orijininin lipit oksidasyonuna duyarlılığı üzerindeki etkisi ile ilgili çelişkili sonuçlar elde edilmiştir. Ma ve ark. [67], tavuk kaslarının, 600 ve $800 \mathrm{MPa}$ basınca maruz kaldıklarında, sığır kasından daha az lipit oksidasyonuna duyarlı olduğunu bildirmişlerdir. Öte yandan, Schindler ve ark. [68], sığır etinin tavuk etinden daha stabil olduğunu, 400 veya $600 \mathrm{MPa}$ 'a kadar yüksek basınçlı işlemlere dayanıklı olduğunu tespit etmişlerdir. Bu işlem oksijenle temas, homojenizasyon, öğ̈̈tme, kıyma ve dilimleme gibi isslemlerle desteklenmekte, böylece oksidasyon genellikle yenilmeye hazır ürünlerinde artırılmaktadır [62, 69]. Ürün formülasyonu da yüksek basınçla uyarılmış lipid oksidasyonunun hızlandırılmasında veya önlenmesinde önemli bir rol oynar. Öte yandan, antioksidan özelliklere sahip bazı katkı maddeleri lipit oksidasyonunu en aza indirebilir. 
Yüksek basınçtan sonra ette oksidasyon hızlanmasının birçok nedeni belirtilmiştir: lipid oksidasyonunu katalize eden demir iyonlarının salınması [66, 70], çiğ tavuk göğüs kasında membran hasarı [63] veya sığır köftesinde adipositlerin yırtılmasıdır [71].

\section{Yüksek Basincin Etin Rengi ve Duyusal Özellikleri Üzerine Etkisi}

Et rengi, tüketicilerin satış noktasında ürünü satın almasını etkileyen önemli bir kalite kriteridir. Bununla birlikte, et rengini, özellikle de çiğ kırmızı et rengini değiştirmek için yüksek basınca gerek duyulduğu bilinmelidir. $L^{*}, a^{*}, b^{*}$ renk skalasındaki Lightness ( $\left.L^{*}\right)$ (Açıklık-koyuluk) bileşeninin, $200 \mathrm{MPa}$ 'ın üzerindeki basınçlarda, sırasıyla, tavuk, domuz ve sığır etinde arttığı bulunmuştur [44, 62, 72]. Bu beyazlatma etkisi, 1 dakika kadar kısa sürelerle yüksek basınçlı işlemlerden sonra ortaya çıkabilir $[44,73]$. Bu durum, yapı ve yüzey özelliklerini etkileyen sarkoplazmik ve/veya myofibriller proteinlerinin çözünürlük kaybına neden olan protein koagülasyonu [71] ya da globin denatürasyonu ve heme grubunun yer değiştirmesi ya da serbest bırakılması [75] ile ilişkili olmuştur. Kırmızı indeksle ilișkilendirilen $a^{*}$ renk bileşeninin, sığır etinde 350-400 MPa üzerindeki basınç işleminden sonra azaldığı da gösterilmiştir [72]. Bu azalma, ferröz miyoglobinin ferrik metmyoglobine oksidasyonuna $[73,76]$ ve muhtemelen kahverengimsi renkten sorumlu olan denatüre olmuş myoglobin ferrik türlerine bağlanmıştır [77]. Yüksek yăg içerĭgi (\%20-25), özellikle sığır köftesi [71] ve domuz sosisinde, et rengi değişimini önemli ölçüde arttırır [78]. Bununla birlikte, çiğ et ürünlerinin çoğu zaman daha fazla pişirilmesi amaçlandığından, yüksek basıncın çiğ et rengi üzerindeki zararlı etkileri genellikle engellenebilir [17, 51]. Bu nedenle, bu hususlar yalnızca "çiğ benzeri” ürün olarak satılması amaçlanan ürünler için geçerli değildir $[62,73]$. Kürlenmiş et ürünleri vb. yenilmeye hazır et ürünleri için, yüksek basıncın et rengini daha az oranda değiştirdiği gözlenmiştir [79, 80]. Ayrıca, yüksek basınca bağlı et renginin değişmesi bazen depolama sırasında kaybolur [76]. Basınçlandırma öncesi ilave edilen ön pişirme ürünleri de renk değişikliğini azaltmada bir başka uygulama olabilir [74].

Yüksek basınçtan kaynaklanan renk, doku, aroma ve lezzet değişiklikleri, yüksek basınçlı işlem görmüş et ürünlerinin duyusal olarak kabul edilmesini sağlar. Bu bakımdan, basınçlı çiğ et ürünleri, esasen renk değişikliği ile ilgili problemler doğurmaktadır [13]. Öte yandan, pişmiş ve işlenmiş et ürünleri genellikle yüksek basınçtan daha az etkilenir ve bu tür ürünlerin ticari değeri daha fazladır.

\section{YÜKSEK BASINÇLI KORUMA VE DEKONTAMINASYONUN AVANTAJLARI-DEZAVANTAJLARI}

Gıdaların muhafazasında yüksek basınç teknolojinin avantajları ve dezavantajları Tablo 1'de listelenmişlerdir [81]. 
Tablo 1. Gıda ürünlerinin korunmasında ve dekontamine edilmesinde yüksek hidrostatik basınç teknolojisinin avantajları ve dezavantajları

\begin{tabular}{|c|c|c|}
\hline \multirow{9}{*}{ Ürünler } & Avantajlar & Dezavantajlar \\
\hline & Su içeriği yüksek olan ürünler için uygundur & $\mathrm{a}_{\mathrm{w}}$ değeri düşük ürünlerde YHB'nin düşük etkisi \\
\hline & Çiğ ürünün lezzet ve tekstürünün pişmiş ürüne yakın & Et tekstürü $\quad$ etkilenir \\
\hline & olmasi & Etin oksidasyonu yüksek basınçla hızlandırılabilir \\
\hline & & $\begin{array}{l}\text { Etin, özellikle kırmızı etin renk bozulması olabilir } \\
\text { Ekmek ve kek gibi hava içeren katı gıdalara, kremalara } \\
\text { uygun değildir }\end{array}$ \\
\hline & Isınma az ya da hiç & \\
\hline & İzostatik işlem, dolayısıyla basınç hem basınç ortamı & \\
\hline & $\begin{array}{l}\text { hem de gıda boyunca hızlı ve düzgün bir şekilde iletilir. } \\
\text { Şekil ve boyuttan bağımsı etki }\end{array}$ & Gerekli sermaye yatırımının yüksek olması nedeniyle \\
\hline & $\begin{array}{l}\text { Mevcut dekontaminasyon teknolojilerinin yetersiz } \\
\text { olduğu ürünler için uygun proses }\end{array}$ & genellikle yüksek değerli ürünlere uygulanamayan süreç \\
\hline \multirow[t]{4}{*}{ Paketleme } & & $\begin{array}{l}\text { Paketleme, yüksek basınç teknolojisine göre } \\
\text { uyarlanmalıdır }\end{array}$ \\
\hline & & $\begin{array}{l}\text { Tamamen sert ambalajlar uygun değildir (konserve gidalar, } \\
\text { cam ambalajlar) }\end{array}$ \\
\hline & $\begin{array}{l}\text { Ürün ambalajı, hacim olarak } \% 15^{\prime} \text { e kadar bir } \\
\text { değişikliği barındırabilen ve ardından sızdırmazlık } \\
\text { veya bariyer özelliklerini kaybetmeden orijinal şekline } \\
\text { geri dönebilen bir ambalajdır }\end{array}$ & $\begin{array}{l}\text { Ambalaj, işlenmiş ürünü deforme etmeyecek şekilde } \\
\text { tasarlanmalıdır }\end{array}$ \\
\hline & & $\begin{array}{l}\text { Kimyasal maddelerin ambalajdan ürüne transferi } \\
\text { ölçülmelidir }\end{array}$ \\
\hline \multirow[t]{3}{*}{$\begin{array}{l}\text { Gıda güvenliği } \\
\text { ve raf ömrü }\end{array}$} & $\begin{array}{l}\text { Bozulmaya neden olan mikroorganizmaları } \\
\text { azaltarak ve enzimleri inaktive ederek raf ömrünün } \\
\text { uzatılması }\end{array}$ & $\begin{array}{l}\text { Laktik asit bakterileri, et endojen florasının en dirençli } \\
\text { grubudur }\end{array}$ \\
\hline & $\begin{array}{l}\text { Gıda kaynaklı patojenleri azaltarak gıda güvenliğini } \\
\text { sağlamak }\end{array}$ & $\begin{array}{l}\text { Bununla birlikte, YHB'nin inaktif bakteri sporlarında } \\
\text { başarısız olduğu bilinmektedir }\end{array}$ \\
\hline & & $\begin{array}{l}\text { Dekontaminasyon verimliliği büyük ölçüde matrise } \\
\text { bağlıdır, bu nedenle HHP'nin ürüne göre incelenmesi } \\
\text { gerekir }\end{array}$ \\
\hline \multirow[t]{4}{*}{ Ekipmanlar } & Toplu işleme ve yarı otomatik işleme mevcut & Proseste hız sınırlayıcı basamak \\
\hline & & Ticari ölçek için yüksek maliyet \\
\hline & & YHB ekipmanındaki karmaşıklık, yapımında, \\
\hline & & $\begin{array}{l}\text { kullanımında ve bakımında son derece yüksek hassasiyet } \\
\text { gerektirir }\end{array}$ \\
\hline Düzenleme & & $\begin{array}{l}\text { Avrupa "Yeni Gıdalar" Yönergesi yasal sorunları dile } \\
\text { getirdi ve yeni basınçlı ürünlerin tanıtımını yavaşlattı. }\end{array}$ \\
\hline
\end{tabular}

\section{GIDALARIN KORUNMASINDA VE DEKONTAMINASYONUNDA YÜKSEK BASINCIN GELECEKTEKİ ROLÜ}

\section{A. Yüksek Değerli ve Yeni Fonksiyonel Ürünler İ̧̧in Isıl Işlem Değişikliği}

Yüksek basınç uygulamaları ısıl işlem ve etlerin gevrekleştirilmesi işlemlerinin, gıda endüstrileri tarafından imal edilen sürülebilir sosisler, karaciğer sosisleri ve pişirilmiş-kürlenmiş et ürünleri imalatında yeni firsatların ortaya çıkmasına katkı sağlayacak bir potansiyele sahiptir [82]. Bu ürünlerdeki geleneksel 1sıl işlemlerin ikame edilmesiyle; tekstürün geliştirilmesi ve duyusal ile besinsel özelliklerin muhafaza edilmesi sağlanabilir [82]. Yüksek basınç, özellikle yüksek değerli ve ısıya duyarlı ürünler için ilginç bir alternatif koruma yöntemini temsil edebilir [10]. Bu ürünler, biyolojik olarak aktif bileşiklerle formüle edilmiş yeni fonksiyonel gıdaları (özel takviyeler, fonksiyonel gıdalar, nutrasötikler ve doğal kişisel bakım ürünleri) içerir. YHB, muhafaza edilmiş biyolojik özelliklere sahip ve patojen içermeyen bileşenler içeren ürünler sağlayarak tüketici ve gıda güvenliği gereksinimlerini karşılayabilir. 


\section{B. Et Yumuşaması}

YHB'nin ikinci potansiyel ortaya çıkma eğilimi, et yumuşamasıdır. Bu proses, belirli şartlarda, hayvanın ölümünden sonra, yüksek basınçta (200 MPa, birkaç dakika) et kesimi yapmaktan ibarettir. Rigor mortis sonrası etlerde yüksek basınç uygulanmasından kaynaklanan sertlikte, bu artışa dayanabilmek için YHB işlemlerinin orta sıcaklıkta $\left(60{ }^{\circ} \mathrm{C}\right)$ yapılması gerekir [53]. Et yumuşaması, yüksek basınçlı işlemden etkilendiği gösterilen katepsinler ve kalpainlerle ilişkilidir [53]. Etin yumuşatılması, gıda endüstrisi için düşük değerli sığır eti ve kuzu eti kesimlerine değer katmanın ilginç bir yolunu temsil edebilir [82].

Son yıllarda yeni yüksek basınçlı teknolojiler ortaya çıkmıştır. Mevcut teknolojiler tarafından karşılanmayan yumuşaklık ve et kalitesi gereksinimlerini karşılamak için hidrodinamik basınç (HDB) veya şok dalgaları geliştirilmiştir [83]. HDB; yüksek enerjili bir patlayıcının sualtı patlamalarından gelen, ses hızını aşan hızlarda, şok dalgalı ön cephe oluşturur [84]. Şok dalga basıncı cepheleri, 70 ila $100 \mathrm{MPa}$, et sıcaklığında, neredeyse hiçbir artış olmadan, milisaniye fraksiyonlarında meydana gelir. HDB; sarkomerin fiziksel olarak parçalanması, miyofibrillerin parçalanması ve etin üzerinde muhtemelen ek bir indirekt yumuşatma etkisi ile etin yumuşamasını sağlar [83]. Yumuşaklık problemleri çoğunlukla kırmızı etleri etkilediğinden, bu teknoloji sığır ve domuz etlerine yöneliktir [84]. Ancak, salamura emilimini, dokusunu ve renk özelliklerini iyileştirmek için hindi eti üzerinde HDB kullanmanın bazı yararları gözlenmiştir [85].

\section{YBP ve Diğer Teknolojilerin Kombinasyonu}

Yüksek basınçlı pastörizasyonun (YBP) bakteri sporlarını inaktive edememesi dikkate alındığında, bu boşluğu doldurmak için ortaya çıkarılmış bir YBP tekniğinin geliştirilmesi hala zordur. YBP ve isı-yüksek basınçlı sterilizasyon (YBS) veya basınç destekli sıcaklık sterilizasyonunun (PATS) kombinasyonu, bu amaç için kullanılabilecek stratejilerden biridir. Örneğin, Zhu ve ark. [86], Clostridium sporogenes sporlarının yüksek sıcaklıkta $\left(80-100{ }^{\circ} \mathrm{C}\right)$, ekstra yağsız kıymadaki yüksek basınçlı yıkım kinetiğini incelemiştir. Clostridium sporlarının bu yöntemle geleneksel ısıl işlemlerden daha kısa sürede tahrip edilebileceği sonucuna varmışlardır.

Yüksek basınç kombinasyonu ve antibakteriyel veya bakteriyostatik maddelerin ilavesi, kapsamlı bir şekilde incelenmiştir. Birçok çalışmada, bakteriyosinlerin ve yüksek basıncın kullanımı araştırılmıştır [16, 21, 25].

\section{SONUÇ}

Yüksek basınç uygulamasının et teknolojisindeki önemi her geçen gün artmaktadır. Et ve et ürünlerinin kalitesini artırmakla birlikte, yeni ürün geliştirmede de kullanılabilmesi mümkün görülmektedir. Ancak yüksek basınç uygulanması ile ilgili yapılan çalışmalar henüz yetersiz olup, daha fazla araştırmaya ihtiyaç bulunmaktadır. Aynı zamanda, bu yöntemin hem avantajları ve hem de dezavantajları bulunmaktadır. Bu açıdan bu durumların daha çok araştırmayla ortaya konulması gerekmektedir. Yüksek basınç teknolojisi ile ilgili yapılan çalışmalar ve pratikte uygulanabilirliği yüksek maliyeti nedeniyle tam olarak uygulama alanı bulamamıştır. Bu nedenle yüksek basınç teknolojisinin pratikte kullanılabilirliği bakımından ekonomik anlamda da avantajlı hale getirilmesi gerekmektedir.

\section{KAYNAKLAR}

[1] Hite, B.H. (1899). The effect of pressure in the preservation of milk. West Virginia University Agricultural Experiment Station Bulletin, 15-35.

[2] Basset, J., \& Macheboeuf, M.A. (1932). Study of the biological effects of ultra-pressures: Resistances of bacteria, diastases and toxins to very high pressures. Comptes Rendus Hebdomadaires des Sceances de l'Academie des Sciences, 195, 1431-1433.

[3] Federighi, M., Tonello, C., De Lamballerie, M., \& Ritz, M. (2001). Les traitements hautes pressions des aliments, in Traitements ionisants et hautes pressions des aliments (eds M. Federighi and J.L. Tholozan), Economica, Paris, pp. 151-227.

[4] Farkas, D.F., \& Hoover, D.G. (2000). High Pressure Processing. Journal of Food Science, 65, 8: 47-64. 
[5] Hugas, M., Garriga, M., \& Monfort, J.M. (2002). New mild technologies in meat processing: High pressure as a model technology. Meat Science, 62, 359-371.

[6] Balasubramaniam, V.M., Farr, S.B., \& Turek, J. (2008). Preserving foods through high pressure processing. Food Technology, 62, 32-38.

[7] Perrier-Cornet, J.-M., Moussa, M., \& Gervais, P. (2009). Applications des hautes pressions hydrostatiques en agroalimentaire. Techniques de l'ingénieur base documentaire: TIB430DUO.

[8] Rastogi, N.K., Raghavarao, K.S., Balasubramaniam, V.M. et al. (2007). Opportunities and challenges in high pressure processing of foods. Critical Reviews in Food Science and Nutrition, 47, 69-112.

[9] Mújica-Paz, H., Valdez-Fragoso, A., Samson, C. et al. (2011) High-pressure processing technologies for the pasteurization and sterilization of foods. Food and Bioprocess Technology, 4, 969-985.

[10] Torres, J.A., \& Velazquez, G. (2005) Commercial opportunities and research challenges in the high pressure processing of foods. Journal of Food Engineering, 67, 95-112.

[11] Tonello, C. (1998). Applications des hautes pressions en agroalimentaire. Techniques de l' Ingenieur, F2, F3220.

[12] Yordanov, D.G., \& Angelova, G.V. (2010) High pressure processing for foods preserving. Biotechnology \& Biotechnological Equipment, 24, 1940-1945.

[13] Oğuzhan, P. 2013. Yüksek Hidrostatik Basınç Teknolojisinin Gıda Endüstrisinde Kullanımı. Fen Bilimleri Enstitüsü Dergisi, 6(2): 205-219.

[14] Nørrung, B., \& Buncic, S. (2008). Microbial safety of meat in the European Union. Meat Science, 78, 1424.

[15] Garriga, M., Grèbol, N., Aymerich, M.T. et al. (2004). Microbial inactivation after high-pressure processing at $600 \mathrm{MPa}$ in commercial meat products over its shelf life. Innovative Food Science \& Emerging Technologies, 5, 451-457.

[16] Jofré, A., Aymerich, T., Grèbol, N., \& Garriga, M. (2009a). Efficiency of high hydrostatic pressure at 600 $\mathrm{MPa}$ against food-borne microorganisms by challenge tests on convenience meat products. LebensmittelWissenschaft und -Technologie, 42, 924-928.

[17] Gola, S., Mutti, P., Manganelli, E. et al. (2000). Behaviour of E. coli 0157:H7 strains in model system and in raw meat by hpp: Microbial and technological aspects. High Pressure Research, 19, 91-97.

[18] Porto-Fett, A.C.S., Call, J.E., Shoyer, B.E. et al. (2010). Evaluation of fermentation, drying, and/or high pressure processing on viability of Listeria monocytogenes, Escherichia coli O157:H7, Salmonella spp., and Trichinella spiralis in raw pork and Genoa salami. International Journal of Food Microbiology, 140, 61-75.

[19] Garriga, M., Aymerich, T., \& Hugas, M. (2002a) Effect of High Pressure Processing on the Microbiology of Skin Vacuum Packaged Sliced Meat Products: Cooked Pork Ham, Dry Cured Pork Ham and Marinated Beef Loin. Report from the Food Microbiology and Biotechnology Unit of IRTA (Institute for Food and Agricultural Research and Technology), Monells, 17 pp.

[20] Morales, P., Calzada, J., Rodriguez, B. et al. (2009) Inactivation of Salmonella enteritidis in chicken breast fillets by single-cycle and multiple-cycle high pressure treatments. Foodborne Pathogens and Disease, 6, $577-581$

[21] Marcos, B., Jofré, A., Aymerich, T. et al. (2008). Combined effect of natural antimicrobials and high pressure processing to prevent Listeria monocytogenes growth after a cold chain break during storage of cooked ham. Food Control, 19, 76-81. 
[22] Chen, H. (2007). Temperature-assisted pressure inactivation of Listeria monocytogenes in Turkey breast meat. International Journal of Food Microbiology, 117, 55-60.

[23] oseki, S., Mizuno, Y., \& Yamamoto, K. (2007). Predictive modelling of the recovery of Listeria monocytogenes on sliced cooked ham after high pressure processing. International Journal of Food Microbiology, 119, 300-307.

[24] Jofré, A., Garriga, M., \& Aymerich, T. (2008). Inhibition of Salmonella sp. Listeria monocytogenes and Staphylococcus aureus in cooked ham by combining antimicrobials, high hydrostatic pressure and refrigeration. Meat Science, 78, 53-59.

[25] Aymerich, T., Jofré, A., Garriga, M., \& Hugas, M. (2005). Inhibition of Listeria monocytogenes and Salmonella by Natural Antimicrobials and High Hydrostatic Pressure in Sliced Cooked Ham. Journal of Food Protection, 68, 173-177.

[26] Garriga, M., Aymerich, T., \& Hugas, M. (2002a). Effect of High Pressure Processing on the Microbiology of Skin Vacuum Packaged Sliced Meat Products: Cooked Pork Ham, Dry Cured Pork Ham and Marinated Beef Loin. Report from the Food Microbiology and Biotechnology Unit of IRTA (Institute for Food and Agricultural Research and Technology), Monells, 17 pp.

[27] Jofré, A., Aymerich, T., \& Garriga, M. (2009b). Improvement of the food safety of low acid fermented sausages by enterocins A and B and high pressure. Food Control, 20, 179-184.

[28] Yuste, J., Pla, R., \& Mor-Mur, M. (2000a). Salmonella enteritidis and aerobic mesophiles in inoculated poultry sausages manufactured with high-pressure processing. Letters in Applied Microbiology, 31, 374-377.

[29] Escriu, R., \& Mor-Mur, M. (2009). Role of quantity and quality of fat in meat models inoculated with Listeria innocua or Salmonella Typhimurium treated by high pressure and refrigerated stored. Food Microbiology, 26, 834-840.

[30] Yuste, J., Pla, R., Capellas, M. et al. (2000b). High-Pressure Processing Applied to Cooked Sausages: Bacterial Populations during Chilled Storage. Journal of Food Protection, 63, 1093-1099.

[31] Rubio, B., Martínez, B., García-Cachán, M.D. et al. (2007a). The effects of high pressure treatment and of storage periods on the quality of vacuum-packed "salchichón" made of raw material enriched in monounsaturated and polyunsaturated fatty acids. Innovative Food Science \& Emerging Technologies, 8, 180-187.

[32] Diez, A.M., Urso, R., Rantsiou, K. et al. (2008a). Spoilage of blood sausages morcilla de Burgos treated with high hydrostatic pressure. International Journal of Food Microbiology, 123, 246-253.

[33] Ruiz-Capillas, C., Carballo, J., \& Jiménez-Colmenero, F. (2007b). Consequences of high-pressure processing of vacuum-packaged frankfurters on the formation of polyamines: Effect of chilled storage. Food Chemistry, 104, 202-208.

[34] López-Caballero, M.E., Carballo, J., \& Jiménez-Colmenero, R. (2002a). Microbial Inactivation in Meat Products by Pressure/Temperature Processing. Journal of Food Science, 67, 797-801.

[35] Carlez, A., Rosec, J.-P., Richard, N., \& Cheftel, J.-C. (1994). Bacterial growth during chilled storage of pressure-treated minced meat. Lebensmittel-Wissenschaft und-Technologie, 27, 48-54.

[36] López-Caballero, M., Carballo, J., Solas, M., \& Jiménez-Colmenero, F. (2002b). Responses of Pseudomonas fluorescens to combined high pressure/temperature treatments. European Food Research and Technology, $214,511-515$. 
[37] Lopez-Caballero, M.E., Carballo, J., \& Jimenez-Colmenero, F. (1999) Microbiological changes in pressurized, prepackaged sliced cooked ham. Journal of Food Protection, 62, 1411-1415.

[38] Diez, A.M., Santos, E.M., Jaime, I., \& Rovira, J. (2008b). Application of organic acid salts and high-pressure treatments to improve the preservation of blood sausage. Food Microbiology, 25, 154-161.

[39] Simpson, R.K., \& Gilmour, A. (1997). The resistance of Listeria monocytogenes to high hydrostatic pressure in foods. Food Microbiology, 14, 567-573.

[40] Jung, S., Tonello Samson, C., \& De Lamballerie, M. (2011). High hydrostatic pressure food processing, in Alternative to conventional food processing, vol. Chapter 6 (ed. A. Proctor), RSC Publishing, pp. 254-306.

[41] Bouton, P.E., Ford, A.L., Harris, P.V. et al. (1977). Pressure-heat treatment of postrigor muscle: Effects on tenderness. Journal of Food Science, 42, 132-135.

[42] Sun, X.D., \& Holley, R.A. (2010) High hydrostatic pressure effects on the texture of meat and meat products. Journal of Food Science, 75, R17-R23.

[43] Ma, H.J., \& Ledward, D.A. (2004). High pressure/thermal treatment effects on the texture of beef muscle. Meat Science, 68, 347-355.

[44] Del Olmo, A., Morales, P., Ávila, M. et al. (2010). Effect of single-cycle and multiple-cycle high-pressure treatments on the colour and texture of chicken breast fillets. Innovative Food Science \& Emerging Technologies, 11, 441-444.

[45] Zamri, A.I., Ledward, D.A., \& Frazier, R.A. (2006). Effect of combined heat and high-pressure treatments on the texture of chicken breast muscle (Pectoralis Fundus). Journal of Agricultural and Food Chemistry, 54, 2992-2996.

[46] Jung, S., Ghoul, M., \& de Lamballerie-Anton, M. (2000a). Changes in lysosomal enzyme activities and shear values of high pressure treated meat during ageing. Meat Science, 56, 239-246.

[47] Ichinoseki, S., Nishiumi, T., \& Suzuki, A. (2006). Tenderizing effect of high hydrostatic pressure on bovine intramuscular connective tissue. Journal of Food Science, 71, E276-E281.

[48] Palamutoğlu, R., Karakaya, M., \& Sarıçoban, C. (2006). Taze ve dondurulmuş sığır Longissimus dorsi kaslarının bazı teknolojik özellikleri üzerine bromelin, ficin ve papain enzimlerinin etkisi. Gıda, 109-116.

[49] Schenková, N., Šikulová, M., Jeleníková, J. et al. (2007). Influence of high isostatic pressure and papain treatment on the quality of beef meat. High Pressure Research, 27, 163-168.

[50] Clariana, M., \& Garcia-Regueiro, J.A. (2011). Effect of high pressure processing on cholesterol oxidation products in vacuum packaged sliced dry-cured ham. Food and Chemical Toxicology, 49, 1468-1471.

[51] Mor-Mur, M., \& Yuste, J. (2003). High pressure processing applied to cooked sausage manufacture: Physical properties and sensory analysis. Meat Science, 65, 1187-1191.

[52] Iwasaki, T., Noshiroya, K., Saitoh, N. et al. (2006). Studies of the effect of hydrostatic pressure pretreatment on thermal gelation of chicken myofibrils and pork meat patty. Food Chemistry, 95, 474-483.

[53] Sikes, A.L., Tobin, A.B., \& Tume, R.K. (2009). Use of high pressure to reduce cook loss and improve texture of low-salt beef sausage batters. Innovative Food Science \& Emerging Technologies, 10, 405-412.

[54] Fernández-Martín, F., Fernández, P., Carballo, J., \& Jiménez Colmenero, F. (1997). Pressure/heat combinations on pork meat batters: Protein thermal behavior and product rheological properties. Journal of Agricultural and Food Chemistry, 45, 4440-4445. 
[55] Yuste, J., Mor-Mur, M., Capellas, M. et al. (1999). Mechanically recovered poultry meat sausages manufactured with high hydrostatic pressure. Poultry Science, 78, 914-921.

[56] Supavititpatana, T., \& Apichartsrangkoon, A. (2007). Combination effects of ultra-high pressure and temperature on the physical and thermal properties of ostrich meat sausage (yor). Meat Science, 76, 555-560.

[57] Chattong, U., \& Apichartsrangkoon, A. (2009). Dynamic viscoelastic characterisation of ostrich-meat yor (Thai sausage) following pressure, temperature and holding time regimes. Meat Science, 81, 426-432.

[58] Jimenez-Colmenero, F., Fernandez, P., Carballo, J., \& Fernandez-Martin, F. (1998). High-pressure-cooked low-fat pork and chicken batters as affected by salt levels and cooking temperature. Journal of Food Science, $63,656-659$.

[59] Cheftel, J.C., \& Culioli, J. (1997). Effects of high pressure on meat: A review. Meat Science, 46, $211-236$.

[60] Chapleau, N., Mangavel, C., Compoint, J.P., \& de Lamballerie-Anton, M. (2004). Effect of high-pressure processing on myofibrillar protein structure. Journal of the Science of Food and Agriculture, 84, 66-74.

[61] Tuboly, E., Lebovics, V.K., Gaál, Ö. et al. (2003). Microbiological and lipid oxidation studies on mechanically deboned turkey meat treated by high hydrostatic pressure. Journal of Food Engineering, 56, 241-244.

[62] Beltran, E., Pla, R., Capellas, M. et al. (2004a). Lipid oxidation and colour in pressure and heat-treated minced chicken thighs. Journal of the Science of Food and Agriculture, 84, 1285-1289.

[63] Orlien, V., Hansen, E., \& Skibsted, L.H. (2000). Lipid oxidation in high-pressure processed chicken breast muscle during chill storage: Critical working pressure in relation to oxidation mechanism. European Food Research and Technology, 211, 99-104.

[64] Andres, A., Adamsen, C., Moller, J. et al. (2006). High-pressure treatment of dry-cured Iberian ham. Effect on colour and oxidative stability during chill storage packed in modified atmosphere. European Food Research and Technology, 222, 486-491.

[65] Campus, M., Flores, M., Martinez, A., \& Toldrá, F. (2008). Effect of high pressure treatment on colour, microbial and chemical characteristics of dry cured loin. Meat Science, 80, 1174-1181.

[66] Cheah, P.B., \& Ledward, D.A. (1997). Inhibition of metmyoglobin formation in fresh beef by pressure treatment. Meat Science, 45, 411-418.

[67] Ma, H.J., Ledward, D.A., Zamri, A.I. et al. (2007). Effects of high pressure/thermal treatment on lipid oxidation in beef and chicken muscle. Food Chemistry, 104, 1575-1579.

[68] Schindler, S., Krings, U., Berger, R.G., \& Orlien, V. (2010). Aroma development in high pressure treated beef and chicken meat compared to raw and heat treated. Meat Science, 86, 317-323.

[69] Fuentes, V., Ventanas, J., Morcuende, D. et al. (2010). Lipid and protein oxidation and sensory properties of vacuum-packaged dry-cured ham subjected to high hydrostatic pressure. Meat Science, 85, 506-514.

[70] Angsupanich, K., \& Ledward, D.A. (1998). High pressure treatment effects on cod (Gadus morhua) muscle. Food Chemistry, 63, 39-50.

[71] Carballo, J., Fernandez, P., Carrascosa, A.V. et al. (1997). Characteristics of low-and high-fat beef patties: Effect of high hydrostatic pressure. Journal of Food Protection, 60, 48-53.

[72] Marcos, B., Kerry, J.P., \& Mullen, A.M. (2010). High pressure induced changes on sarcoplasmic protein fraction and quality indicators. Meat Science, 85, 115-120. 
[73] Jung, S., Ghoul, M., \& de Lamballerie-Anton, M. (2003). Influence of high pressure on the color and microbial quality of beef meat. Lebensmittel-Wissenschaft und-Technologie, 36, 625-631.

[74] Goutefongea, R., Rampon, V., Nicolas, J., \& Dumont, J. (1995). Meat Color Changes Under High Pressure Treatment. Proceeding of the 41st International Congress of Meat Science and Technology, San Antonio, Texas.

[75] Carlez, A., Veciana-Nogues, T., \& Cheftel, J.-C. (1995). Changes in colour and myoglobin of minced beef meat due to high pressure processing. Lebensmittel-Wissenschaft und-Technologie, 28, 528-538.

[76] Cava, R., Ladero, L., Gonzalez, S. et al. (2009). Effect of pressure and holding time on colour, protein and lipid oxidation of sliced dry-cured Iberian ham and loin during refrigerated storage. Innovative Food Science \& Emerging Technologies, 10, 76-81.

[77] Wackerbarth, H., Kuhlmann, U., Tintchev, F. et al. (2009). Structural changes of myoglobin in pressuretreated pork meat probed by resonance Raman spectroscopy. Food Chemistry, 115, 1194-1198.

[78] Colmenero, F.J., Carballo, J., Fernández, P. et al. (1997). High-pressure-induced changes in the characteristics of low-fat and high-fat sausages. Journal of the Science of Food and Agriculture, 75, 61-66.

[79] Karłowski, K., Windyga, B., Fonberg-Broczek, M. et al. (2002). Effects of high pressure treatment on the microbiological quality, texture and colour of vacuum packed pork meat products. High Pressure Research, $22,725-732$.

[80] Rubio, B., Martínez, B., García-Cachán, M.D. et al. (2007b). Effect of high pressure preservation on the quality of dry cured beef “Cecina de Leon”. Innovative Food Science \& Emerging Technologies, 8, $102-110$.

[81] Kadam, P.S., Jadhav, B.A., Salve, R.V., \& Machewad, G.M. (2012). Review on the high pressure technology (HPT) for food preservation. Journal of Food Processing \& Technology, 3, 135.

[82] Purroy-Balda, F., Val Aparicio, B., \& Tonello, S.C. (2012). Industrial high pressure processing of foods: Review of evolution and emerging trends. Journal of Food Science and Engineering, 2, 543-549.

[83] Bajovic, B., Bolumar, T., \& Heinz, V. (2012). Quality considerations with high pressure processing of fresh and value added meat products. Meat Science, 92, 280-289.

[84] Solomon, M.B., Liu, M.N., Patel, J.R. et al. (2010). Hydrodynamic Pressure Processing to improve meat quality and safety, in Advanced Technologies for Meat Processing vol. Chapter 9 (eds L.M.L. Nollet and F. Toldra), CRC Press, Taylor \& Francis, New York, pp. 219-244.

[85] Bowker, B.C., Callahan, J.A., \& Solomon, M.B. (2010). Effects of hydrodynamic pressure processing on the marination and meat quality of turkey breasts. Poultry Science, 89, 1744-1749.

[86] Zhu, S., Naim, F., Marcotte, M. et al. (2008). High-pressure destruction kinetics of Clostridium sporogenes spores in ground beef at elevated temperatures. International Journal of Food Microbiology, 126, 86-92. 